problem presented by the high cost of research equipment, more especially in certain critical fields of study, which are by no means always easy to identify, and which may require special scrutiny and decision on more than a scientific basis alone. Nevertheless, so far as the overall progress of science is concerned, he insists that the judgment of the active research worker should be the determining factor, and that the central planning and direction which are inevit. able in development would be detrimental to scientific advance.

Generally, Dr. Waterman agrees that in spite of repeated emphasis on the importance of basic research, in the United States support has not been forthcoming on a scale sufficient to enable such research to hold its own in relation to the larger and seemingly more pressing problems of development. Although the position may be somewhat better in Great Britain, the experience of the National Science Foundation during the past decade affords no ground for complacency. The problems confronting the Foundation are similar in many ways to those facing the Advisory Council for Scientific Policy, and it is apparent that there are certain respects in which the Minister for Science might well take steps to see that these problems are tackled with more urgency and determination, and that the necessary co-ordination and financial support are forthcoming, even if it involves raising issues at Cabinet-level. Finally, the reader of this report can scarcely fail to note how much in it supports the argument advanced in the report, Increasing the Effectiveness of Western Science, for making the utmost possible use of possibilities of international co-operution in the attack on such major problems as space research, oceanography, polar research and the like.

\section{THE PROCESSES OF DEVELOPMENT}

\section{The Biochemistry of Development}

By Prof. Jean Brachet. (International Series of Monographs on Pure and Applied Biology. Division : Modern Trends in Physiological Sciences, Vol. 2.) $\mathrm{Pp}$. xii +320 . (London and New York: Pergamon Press, 1960.) 65s. net.

$\mathrm{I}^{\mathrm{N}}$ N the years since the Second World War, biochemistry, which began with an interest in how living systems maintain themselves, has begun to find itself in a position to tackle the much more difficult question of how they come into being. Chemical embryology may be said to have become a separate branch of study with the publication of J. Needham's great three-volume treatise in 1931. Even that was mainly concerned with the maintenance metabolism of embryos, and it was only with the publication of the same author's Biochemistry and Morphogenesis in 1942, and J. Brachet's Embryologie Chimique in 1944, that the study of the chemical processes by which development itself takes place acquired a massive impetus. Brachet's classical book was revised and translated into English in 1950 , and since then he has published another extensive survey of similar ground, in his Biochemical Cytology of 1957. In the present book, he returns to embryology. The work is, as he points out in the foreword, to be considered as a summary of the advances that have been made since the last edition of his Chemical Embryology. In general, it follows the plan of that book, with successive chapters on gametogenesis, fertilization, cleavage, two chapters on the chemical embryology of invertebrate and of vertebrate eggs, nucleo-cytoplasmic interactions during morphogenesis, and finally, the biochemistry of differentiation.

Prof. Brachet modestly discounts any claim to treat these subjects in a complete and exhaustive manner, emphasizing that he is concerned only with reviewing the recent advances. However, as we have learnt to expect from this author, the subjects which he chooses to treat include nearly all the topies which have attracted the attention of embryologists in recent years. Moreover, they are discussed on the basis of his well-known combination of $e x$ tremely wide reading and considerable, original, and largely unpublished, observations by himself and his collaborators. The result is a book which has, on one hand, the merits of a very valuable work of reference, but which is also something much more, in that it presents a most stimulating general synthesis of the field as it is seen by one of the most active contributors to it. The recent period in embryology has been remarkable for the number and power of the new technical methods which have been made available for the investigation of developing systems. We have seen, in particular, the introduction of refined biochemical methods for studying the nucleic acids, and such technical advances as the use of tracers, electrophoresis, immunological methods, the electron microscope, nuclear transplantation, and so on. Brachet and workers in his laboratory have themselves used many of these methods, and he writes with real authority about them.

Perhaps Brachet's most characteristic contribution to our general theories of embryonic development is his emphasis on the importance of gradients of ribonucleic acid content in various regions of the egg and embryo. In this book also, the evidence on this subject is fully discussed, and a number of as yet unpublished observations are described. To me it seems that, although there is undoubtedly a great deal of importance in Brachet's concept of nucleic acid gradients, the conception does not do adequate justice to the undoubted existence of an enormously elaborate system of specific types of ribonucleic acid and protein. Indeed, biochemistry is probably not yet equipped to tackle this aspect of the matter. It is primarily the study of genetics which leads us to realize that any given cell probably contains hundreds, if not thousands, of different species of ribonucleic acid and protein. If any criticism is to be offered of Brachet's book, it is that one would like to have seen more genetics in it. Perhaps, however, it is unreasonable to ask for so much. A satisfactory synthesis between genetics and biochemical embryology is what we are all seeking, and one can scarcely demand of an author that he should provide something that no one has yet been able to formulate. We have enough to be grateful for in a work which deals with the whole biochemical side of development in a manner which is both thorough and also controversial enough to be stimulating. 